\title{
Re-evaluation of the role of trainee psychiatrists in secluding general adult psychiatric patients
}

\author{
M. F. Okhai and P. M. McLaren
}

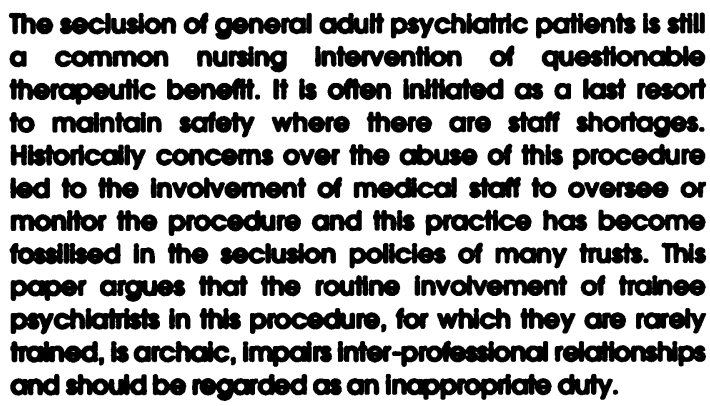

The Royal College of Psychiatrists (1990) defines seclusion as the supervised confinement of a patient specifically placed alone in a locked room for a period of any time of the day or night for the protection of the patient, staff, or others from serious harm. The Royal College of Nursing (RCN; 1979) defines seclusion as 'a means of dealing with severely disturbed behaviour where there is an immediate danger to the patient or others'. The RCN recommended that seclusion should only be used when other means to contain a situation have been exhausted but recognised that, particularly because of staff shortages, it may from time to time be a necessary procedure.

\section{Fistorical development}

Seclusion evolved in the care of the mentally ill as a result of the successful abolition of mechanical restraints in the early nineteenth century. It had been common practice to restrain patients for long periods. A visitor, Edward Wakefield (17741854), 'discovered' James Norris in Bethlem Hospital in 1814, where he had been chained to a wall for 14 years. Phillipe Pinel (1745-1826) who was appointed to the Bicetre (a public mental hospital) in Paris in 1793, found a patient who had been chained for 40 and another who had been chained for 36 years (Jones, 1983). John Connolly (1794-1866) introduced the practice of non-restraint to Middlesex, into what was then Britain's largest asylum with 1000 beds, and supported, as an alternative, the use of seclusion to control extreme violence and agitation (Cranmer, 1990). Cranmer cites Samuel Gaskell (1807-1886) as supporting seclusion as an alternative to mechanical restraint.

In spite of these recommendations there was no statutory basis for the use of seclusion until the Lunacy (Consolidation) Act of 1890. Under this act seclusion was not to be initiated by the nursing staff. The medical superintendent could order seclusion by writing, 'in a special book', the need for and duration of the seclusion. The secluded patient had to be inspected every 30 minutes and a report made in writing. The asylum inspectors could then ascertain how many patients were being secluded, for how long and for what reason. This was intended to minimise the use of seclusion. The Mental Health Act of 1959 abolished the legal rules relating to seclusion and there has been no statutory basis for seclusion since the 1890 Act. Seclusion has remained in legal limbo and its therapeutic role is equally uncertain. The Code of Practice to the Mental Health Act of 1983 states "Although it falls within the definition of medical treatment in the Mental Health Act (section 145), seclusion is not a treatment technique" (Department of Health and Welsh Office, 1983). It also states "its sole aim, therefore, is to contain severely disturbed behaviour which is likely to cause harm to others". The Code of Practice noting that seclusion is not regulated by statute goes on to say "Where the decision is made by someone other than a doctor, then the necessary arrangements must be made for a doctor to attend immediately".

\section{The psychiatrist and seclusion}

To comply with the Code of Practice, trusts incorporate a review procedure by a doctor into their seclusion policies. This usually involves the duty doctor visiting the ward after the patient 
has been secluded, to confirm that its use was necessary. This is not something that trainee psychiatrists are usually trained to do. Seclusion is largely ignored in the medical literature. Neither of the two major textbooks in psychiatry list seclusion in the index (Gelder et al, 1989; Kendell \& Zeally, 1993). Alty \& Mason (1994) point out "In reality although the responsible medical officer may sanction the use of seclusion they invariably have little to do with it". These authors also emphasise the primacy of nursing in the operation of seclusion and point out that nurses bear the brunt of operating a seclusion procedure. In their words "seclusion without doubt falls within the nursing domain".

\section{Should trainee psychiatrists have a role in seclusion?}

An important effect of the New Deal for Junior Doctors' (Department of Health, 1991) was an examination of the duties junior doctors were being asked to perform, to identify those which could be better performed by other professional groups, such as nurses, in order to facilitate the required reductions in working hours. Unfortunately this process of identifying inappropriate duties received little attention in psychiatry, probably because the problem of working hours was not so severe, and an important opportunity to review the working practices of trainee psychiatrists was missed. The routine involvement of the trainee psychiatrist in seclusion could be regarded as such an inappropriate duty. The development of smaller community based in-patient units served by junior doctors based at home or at one site may mean that a doctor has to travel many miles at night just to review a patient in a seclusion room and sign a seclusion book. The result may be that a patient is kept in seclusion, longer than would otherwise be the case, waiting for the doctor to arrive.

Checking on the use of seclusion can be done more effectively and efficiently by the nurse manager on duty who is likely to have had training in the use of seclusion and be aware of the dangers. A trainee psychiatrist with no training in the use of seclusion is unlikely to prove an effective check on the appropriate use of seclusion. The procedure is also demeaning to the professionalism of nursing staff. Clinical audit is another tool for review and patients who had been secluded could be debriefed by the senior nurse on the ward after release. It is of course appropriate for the doctor to attend if the patient has been injured or their treatment needs to be reviewed immediately.

In summary, the established policy of having a trainee psychiatrist always review the use of seclusion by nursing staff is anachronistic and serves no useful purpose. More effective mechanisms for reviewing the use of seclusion should be put in place within the nursing profession. If psychiatrists are to be involved they should receive appropriate training in the uses and abuses of seclusion.

\section{References}

ALTY, A. \& MASON, M. (1994) Seclusion and Mental Health. London: Chapman \& Hall.

Cranmer, J. (1990) Asylum History. London: Gaskell.

DEPARTMENT OF HEALTH (1991) Junior Doctors. The New Deal: Making the best use of the skills of Nurses and Midwives. London: NHS Management Executtve.

DEPARTMENT OF HEALTH AND WELSH OFFTCE (1983) Code of Practice for Mental Health Act 1983. London: HMSO.

GELDER, M., GATH, D. \& MAYOU, R. (1989) Oxford Textbook of Psychiatry (2nd Edn.). Oxford. Oxford University Press.

JONES, W. L. (1983) Ministering to Minds Diseased. London: William Heinemann.

KENDELL, R. E. \& ZEALLY, A. K. (1993) Companion to Psychiatric Studies (5th Edn). Edinburgh: Churchill Ltvingstone.

Royal College of Psychiatrists (1990) The seclusion of psychiatric patients. Psychiatric Bulletin, 14, 500-501.

ROYAL COLLGE OF NURSING. SOCIETY OF PSYCHIATRIC NURSING (1979) Seclusion and Restraint in Hospitals and Units for the Mentally Disordered. London: RCN.

*M. F. Okhai, Registrar in Psychiatry, St. Martin's Hospital, Littlebourne Road, Canterbury CT1 1AZ; and P. M. McLaren, Senior Lecturer in Psychiatry. UMDS Division of Psychiatry and Psychology. Guy's Hospital SE1 9RT

*Correspondence 